\title{
Leber plus disease
}

INSERM

\section{Source}

INSERM. (1999). Orphanet: an online rare disease and orphan drug data base. Leber plus disease. ORPHA:99718

Leber 'plus' disease describes patients with the clinical features of Leber's hereditary optic neuropathy (LHON; see term) in combination with other serious systemic or neurological abnormalities. These abnormalities include: postural tremor, motor disorder, multiple sclerosis-like syndrome, spinal cord disease, skeletal changes, Parkinsonism with dystonia, anarthria, dystonia, motor and sensory peripheral neuropathy, spasticity and mild encephalopathy. It is caused by maternally-inherited mitochondrial DNA (mtDNA) mutations. 